\title{
$1 \quad$ Predicting coral adaptation to global warming in the Indo-West-Pacific
}

2

51 University of Texas at Austin, USA;

62 Deakin University, Australia;

73 Cornell University, USA

8

$9 *$ corresponding author, matz@utexas.edu , +1-512-992-8086

10

11 Keywords: metapopulation, adaptation, genetic rescue, individual-based modelling, assisted gene

12 flow

13

$14 \quad$ Paper type: Primary Research Article 


\section{ABSTRACT}

17 The potential of reef-building corals to adapt to increasing sea surface temperatures is often

18 speculated about but has rarely been comprehensively modeled on a region-wide scale. Here, we

19 used individual-based simulations to model adaptation to warming in a coral metapopulation

20 comprising 680 reefs and representing the whole of the Central Indo-West Pacific. We find that

21 in the first century of warming (approximately from 50 years ago to 50 years in the future) corals

22 adapt rapidly by redistributing pre-existing adaptive alleles among populations ("genetic

23 rescue"). In this way, some coral populations - most notably, Vietnam, Japan, Taiwan, New

24 Caledonia, and the southern half of the Great Barrier Reef - appear to be able to maintain their

25 fitness even under the worst warming scenarios (at least in theory, assuming the rate of evolution

26 is the only limitation to local coral recovery). Still, survival of the majority of reefs in the region

27 critically depends on the warming rate, underscoring the urgent need to curb carbon emissions.

28 Conveniently, corals' adaptive potential was largely independent of poorly known genetic

29 parameters and could be predicted based on a simple metric derived from the biophysical

30 connectivity model: the proportion of recruits immigrating from warmer locations. We have

31 confirmed that this metric correlates with actual coral cover changes throughout the region,

32 based on published reef survey data from the 1970s to early 2000s. The new metric allows

33 planning assisted gene flow interventions to facilitate adaptation of specific coral populations. 


\section{INTRODUCTION}

37 The world has been warming at an unprecedented rate for the past half century (Pachauri, Mayer,

38 \& Intergovernmental Panel on Climate Change, 2015). This brings about major ecological

39 changes (Parmesan, 2006), among which the worldwide decline of coral reefs is one of the most

40 alarming (O. Hoegh-Guldberg et al., 2007). Several highly cited publications have asserted that

41 natural evolution is too slow to allow corals to adapt to global warming (O. Hoegh-Guldberg,

42 1999; O. Hoegh-Guldberg et al., 2007; Ove Hoegh-Guldberg, Poloczanska, Skirving, \& Dove,

43 2017); however, this view is debatable. The scenario envisioned in these papers is "evolutionary

44 rescue": adaptation via the origin and spread of entirely novel adaptive mutations (Orr, 2005).

45 This would indeed be slow, as well as poorly predictable without knowledge of such elusive

46 parameters as mutation rate, number of potentially adaptive loci, and mutational effect size.

47 However, the first-order evolutionary response in natural populations rarely involves new

48 mutations; instead, it is based on adaptive alleles pre-existing in a population, collectively called

49 “standing genetic variation” (Barrett \& Schluter, 2008; Hermisson \& Pennings, 2005;

50 Savolainen, Lascoux, \& Merilä, 2013). This mode of adaptation can be very rapid (Campbell-

51 Staton et al., 2017; Lescak et al., 2015). In a metapopulation in which a species is distributed

52 across multiple locally adapted sub-populations, there is also a possibility of rapid adaptation

53 through "genetic rescue" (Whiteley, Fitzpatrick, Funk, \& Tallmon, 2015), which involves

54 redistribution of pre-existing locally adaptive alleles between populations through migration

55 when conditions start to change. Several recent papers argued that this particular mode of

56 adaptation is likely to be of major importance for reef-building corals as they adapt to warming

57 (Bay, Rose, Logan, \& Palumbi, 2017; Kleypas et al., 2016; Matz, Treml, Aglyamova, \& Bay,

58 2018). Indeed, all coral species exist across a considerable gradient of temperatures while 
59 genetically adapting to local thermal conditions (Bay \& Palumbi, 2014; Dixon et al., 2015;

60 Palumbi, Barshis, Traylor-Knowles, \& Bay, 2014) and exchanging migrants over very long

61 distances (Ayre \& Hughes, 2004; I. B. Baums, Miller, \& Hellberg, 2005; Matz et al., 2018;

62 Romero-Torres, Treml, Acosta, \& Paz-García, 2018), which appears to set the perfect stage for

63 genetic rescue (Matz et al., 2018; Torda et al., 2017).

65 Here, we aimed to identify factors affecting the corals' potential to survive under warming across

66 the central Indo-West Pacific, the ocean region where the majority of the world's coral reefs are

67 found (Fig. 1 A). We have extended our earlier individual-based model of metapopulation

68 adaptation (Matz et al., 2018) to capitalize on the non-Wright-Fisher framework available in the

69 simulation software SLiM 3.3 (Haller \& Messer, 2019). This framework allows for overlapping

70 generations, age structure within populations, age-specific mortality, and involves natural

71 dependence of population size on fitness. The new model

72 (https://github.com/z0on/coral triangle SLiM model) was parameterized with the number of

73 populations, reef habitat sizes, and connectivity pattern expected for a reef-building coral of

74 genus Acropora (Treml, Roberts, Halpin, Possingham, \& Riginos, 2015; Treml et al., 2012). Our

75 model included a period of long-term adaptation to temperatures fluctuating around a location-

76 specific mean followed by the onset of location-specific warming as predicted under RCP 4.5 or

77 RCP 8.5 (Fig. S1 (Alvich, n.d.)). We have explored the influence of warming rate, population

78 turnover rate (modulated through juvenile mortality), and genetic parameters affecting the

79 efficiency of selection (heritability, plasticity) or amount of genetic variation (number of

80 quantitative trait loci, mutation rate, and mutation effect size). Lastly, we have compared our 
81 results to the actual coral cover changes observed throughout the region by early 2000s (Bruno \&

82 Selig, 2007).

83

84

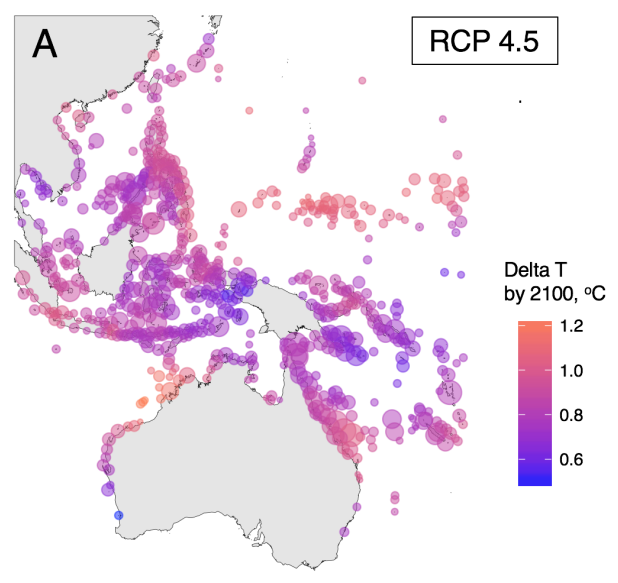

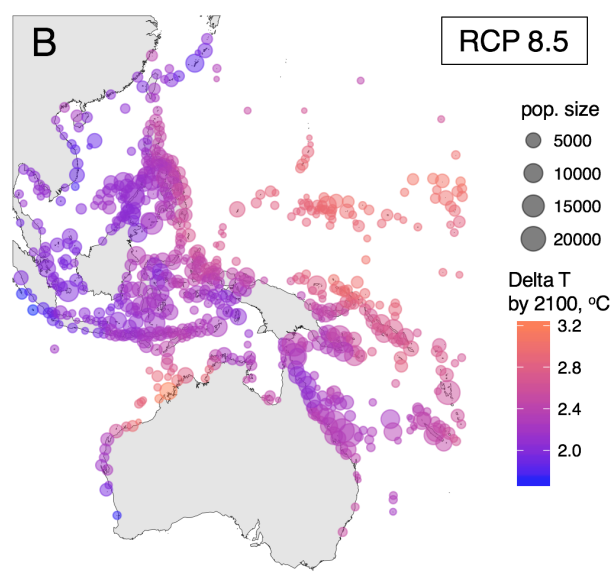

85 Figure S1. Modeled warming scenarios. Size of the points indicates carrying capacity of the population

86 (see legend on panel B).

87

88 MATERIALS AND METHODS

Non-Wright-Fisher model

90 Compared to our earlier model (Matz et al., 2018), the new model uses a "forward migration"

91 matrix, giving probabilities for an offspring produced at a given location to settle at all locations

92 (including the natal one), instead of the original "immigration" matrix (giving, per location,

93 proportions of immigrants from all locations). The non-Wright-Fisher formulation also made it

94 possible to track the statistic that is meaningful for coral ecology - coral cover - as a proportion

95 of the available carrying capacity occupied. The model also outputs (per population) a set of

96 metrics: mean phenotype, mean fitness, number of segregating mutations at the QTLs, standard

97 deviation of breeding value, mean age of adults, number of adults, and adult mortality in the last generation. The model code (https://github.com/z0on/coral triangle SLiM model) reads habitat 
99 sizes, the migration matrix, and environmental settings from external files, while the major

100 population-genetic parameters (see next paragraph) are supplied as external arguments. This

101 makes the model easy to repurpose for any metapopulation-evolution scenario.

102

103

Main parameter settings

104 Other than transitioning to the non-Wright-Fisher framework, the model remained very similar 105 to the original one (Matz et al., 2018) in structure. We used conservative parameters both in 106 terms of allowed genetic variation and factors affecting the efficiency of selection. We assumed 107100 additive quantitative trait loci (QTLs) affecting an individual's thermal optimum, with new 108 mutations having subtle effects following the distribution $N\left(0,0.03^{\circ} \mathrm{C}\right)$. With these settings and 109 in the absence of selection the mutational process would have resulted in standard deviation in 110 the thermal optimum of only $0.1^{\circ} \mathrm{C}$ in a population. The genetically determined thermal optimum

111 (breeding value) of an individual was calculated as the sum of the effects of all QTLs, and the 112 actual phenotype was then computed by adding a random value drawn from $N\left(0,0.5^{\circ} \mathrm{C}\right)$ to

113 model imperfect heritability. The fitness of an individual was computed based on the difference

114 between its phenotype and the environmental temperature at its location, given a Gaussian fitness

115 curve with a standard deviation of 1; this fitness function implies that an individual's fitness

116 would drop by about $40 \%$ if its phenotype were mismatched with the local temperature by $1{ }^{\circ} \mathrm{C}$.

118 Reproduction and age-related mortality

119 Each Acropora individual produces $10^{5}-10^{6}$ eggs per yearly spawning event but the vast 120 majority of these offspring die as larvae or very young recruits without giving rise to a new

121 colony. We assumed that each adult coral produces just a single surviving recruit per year, and 
122 that recruit still has a 10-fold higher chance of mortality in its first year compared to an adult of

123 the same phenotype. Second-year juveniles had a 1.5-fold higher chance of mortality than adults;

124 in the third year the surviving corals become reproducing adults (Baria, dela Cruz, Villanueva, \&

125 Guest, 2012). This age-specific mortality profile resulted in average adult coral age, prior to

126 warming, of approximately 10 years, which is reasonable for fast-growing acroporids.

Habitat size and genetic variation

129 The critical parameter determining the total amount of genetic variation available to selection is

130 the product of population size and mutation rate. Here, we assumed that the smallest reefs

131 (completely enclosed within a single $10 \times 10 \mathrm{~km}$ cell) could contain 100 corals, and larger reefs

132 had more carrying capacity, proportionally to the number of 10x10km cells they occupied (up to

13320,000 corals per reef). While these numbers are on par with genetic estimates of effective

134 population sizes (Matz et al., 2018), they are much lower than census sizes. We kept our

135 population sizes low to keep the model conservative (i.e., limiting for adaptation) and also faster-

136 running, but compensated for it by assuming a mutation rate on the upper boundary of values

137 reported in the literature, 1e-5 per QTL per generation (Barton \& Turelli, 1989). In our earlier

138 model (Matz et al., 2018), this mutation rate allowed for indefinite adaptation based on novel

139 adaptive mutations (evolutionary rescue).

141 Environment

142 Location-specific temperatures were based on the mean yearly temperature at each location (Fig.

143 1A) during the genetic equilibration period (see below), after which warming was imposed with

144 a location-specific rate predicted under either RCP 4.5 or RCP 8.5 (Fig. S1 (Alvich, n.d.)). We 
145 explored three models of temperature variation (to which warming was added): constant,

146 fluctuating as a sine wave with a period of 5 years and amplitude of $0.5^{\circ} \mathrm{C}$ (to approximate El

147 Niño cycles (Quinn, Taylor, \& Crowley, 1993)), and random temporally uncorrelated

148 fluctuations with an amplitude drawn from a normal distribution using the standard deviation of

149 temperatures empirically observed at each location. These three environmental models yielded

150 nearly identical results, and so all the figures presented here correspond to the sinusoidal model.

\section{Parameter variations}

153 For each parameter we tried a different setting in addition to the setting in the "main run",

154 summarized in Fig. 3. The "Fewer QTLs" scenario involved 10 QTLs (instead of 100) with 3-

155 fold higher possible mutational effects; i.e., drawn from $N\left(0,0.1^{\circ} \mathrm{C}\right)$ instead of $N\left(0,0.03^{\circ} \mathrm{C}\right)$.

156 This adjustment of the mutation effect distribution was done to preserve the mutational genetic

157 variation, which is the square of the standard deviation of mutation effects times the number of

158 QTLs. In the "Low juvenile mortality" scenario, first-year recruits were only two times (as

159 opposed to ten times) more likely to die as adults, and in the second year their survival was only

$16010 \%$ lower than adults. This scenario resulted in an average adult age of 6.5 years. The "Lower

161 plasticity" scenario used a narrower fitness function, implying that the fitness of an individual

162 would drop by $86 \%$ (instead of $40 \%$ ) when its phenotype mismatches the environment by $1^{\circ} \mathrm{C}$.

163 The "Higher heritability" scenario had a smaller random value added to the breeding value when

164 computing phenotype; this resulted in a heritability of 0.4 in locally adapted populations prior to

165 warming, compared to 0.15 in the main run. The "Lower mutation rate" scenario used a tenfold

166 lower rate, and the "Lower mutation effect" scenario drew effect sizes from $N\left(0,0.01^{\circ} \mathrm{C}\right)$, 
167 threefold lower than in the main run. Populations in the "Larger populations" scenario were

168 twofold larger, with two corals per $\mathrm{km}^{2}$.

170 Migration

171 The movement of individuals among sub-populations of Acropora was estimated using our

172 biophysical model of larval dispersal for the Indo-Pacific (Treml et al., 2015, 2012). This model

173 incorporates hydrodynamic data (1/12 \& daily resolution for 1992-2012 ("HYCOM Data

174 Acknowledgement Statement," n.d.)), coral reef habitat maps (“Ocean Data Viewer,” n.d.), and

175 biological parameters for coral larvae. In this model, dispersing larvae were represented by their

176 i) spawning time following two summer full moons, ii) larval settlement window from 6 days to

17760 days (maximum larval duration (Connolly \& Baird, 2010)), iii) daily larval mortality (5\%

178 (Connolly \& Baird, 2010)) and iv) passive behavior while distributed in the top 10 meters of the

179 ocean. In this model, larvae are moved throughout the seascape following spawning using an

180 efficient and $4^{\text {th }}$ order accurate advective transport scheme (Smolarkiewicz, 1983). A detailed

181 model description and sensitivity analysis is available in (Treml et al., 2012). The results from

182 the dispersal simulations were used to create a long-term average forward transition matrix

183 quantifying the likelihood that larvae spawned at a source reef survive and settle to all potential

184 reef sites (including the natal source patch).

186 Genetic equilibration

187 The model used the same stepwise procedure to rapidly achieve genetic equilibrium as the

188 original model used (Matz et al., 2018). The first 2000 years were run with population sizes 25-

189 fold smaller but mutation rate 25 -fold higher than target values, followed by 2000 years of 10 - 
190 fold smaller population sizes / 10-fold higher mutation rate. The remaining years were run at the

191 target population sizes and mutation rates; the warming began at year 5500. In this way, the

192 product of population size and mutation rate that governs the overall genetic variation is constant

193 throughout the simulation, but the genetic equilibrium is approached substantially faster due to

194 the smaller population size at the beginning of the simulation. We have confirmed that the

195 genetic variation stays constant in the last 200 years preceding warming (Fig. S2), so the

196 adaptation to warming starts from a state of genetic equilibrium.

198 Model runs and results processing

199 The analysis focused on the 400-year window centered on the start of warming. All models were

200 run five times with different random seeds; the decadal averages for each run were averaged

201 among runs. The coral cover per site was computed as the number of adults divided by the

202 carrying capacity of the site. The coral cover response (Fig. 3) was computed as the difference

203 between coral cover after 100 or 200 years of warming and coral cover in the pre-warming

204 decade, divided by the pre-warming cover. Reef declines plotted in Fig. 2 are absolute values of

205 responses for reefs that experienced declines (more than 95\% of all reefs).

207 Matching with actual reef survey data

208 Bruno and Selig (Bruno \& Selig, 2007) have compiled coral surveys across the Indo-Pacific

209 from the 1970 s to early 2000 s, to quantify region-wide coral declines. To match the locations of

210 surveyed and simulated reefs, we clustered all reefs into groups within distance corresponding to

211 one degree of latitude $(111 \mathrm{~km})$ from each other, and selected clusters that (i) contained both

212 simulated and real reefs, (ii) contained real reefs surveyed $>15$ years apart, and (iii) contained a 
213 reef survey completed after 2000. All the real reef data within each cluster were then used to

214 compute a regression coefficient of coral cover against year. Essentially, this analysis treats all

215 surveys of reefs within a local cluster as replicate surveys of the same reef (very few individual

216 reefs were actually surveyed repeatedly over a long period). These "real-change" regression

217 coefficients were compared to the mean environmental predictor value, or to the mean model-

218 predicted coral cover response, across virtual reefs within the same cluster.

220 RESULTS

221 Prior to warming, adult coral cover at each site stabilized at similar levels across most models

222 (Fig. S2), indicating that populations were nearly equally successful at local adaptation

223 irrespective of most parameter settings. There were a few exceptions. The cover was lower

224 under low plasticity, which is explained by lower mean population fitness under this setting, and

225 under low juvenile mortality, which leads to a smaller proportion of adults in each population.

226 Conversely, the cover was higher under higher heritability due to the higher mean population

227 fitness attainable under this setting. The within-population standard deviation of breeding value

228 (square root of genetic variation) stabilized at approximately $0.2^{\circ} \mathrm{C}$ (Fig. S2). The stability of this

229 value in pre-warming generations indicates that genetic equilibrium has been reached. Notably,

230 pre-warming genetic variation was similar irrespective of the model's settings (Fig. S2),

231 indicating that the same amount of standing genetic variation was available to selection at the

232 onset of warming. The stability of this value irrespective of settings that affect the number of

233 new mutations arising each generation (population size or mutation rate) suggests that standing

234 genetic variation in this system predominantly depends on migration-selection balance rather

235 than on mutational input. 

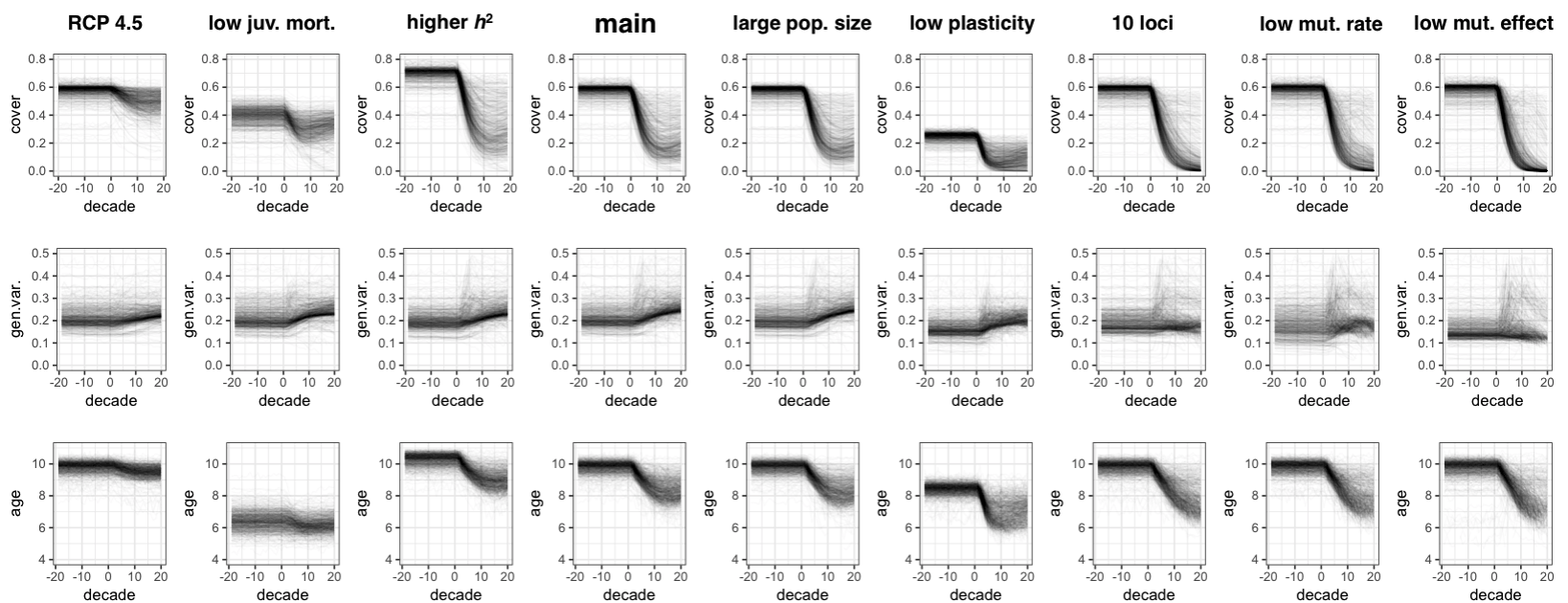

Figure S2. Profiles of coral cover ( \% of occupied carrying capacity, top row), standard deviation of breeding value (i.e., square root of genetic variation, middle row), and mean adult age (bottom row) under

240 different parameter settings. The settings are identified above the columns and correspond to settings

241 listed in Fig. 3. The $x$-axis is decade since the start of warming; the $y$-axis is the value at a particular reef.

242 On each panel, traces for all 680 reefs are overlaid. Note that in all cases the most dramatic change

243 happens within the first 10 decades of warming.

245 The mean age of adult corals was also similar - about 10 years - both among populations and

246 model runs (Fig. S2), which is a reasonable number for fast-growing Acropora corals (Baria et

247 al., 2012). There were three exceptions: the mean age was higher under high heritability, lower

248 under low plasticity, and much lower under low juvenile mortality. Higher heritability leads to

249 older corals because of their higher average fitness and therefore lower yearly risk of mortality,

250 and conversely, younger average age under low plasticity is explained by lower fitness and

251 higher risk of mortality. Younger average age under low recruit mortality is a direct consequence

252 of more young corals surviving in the first year. 

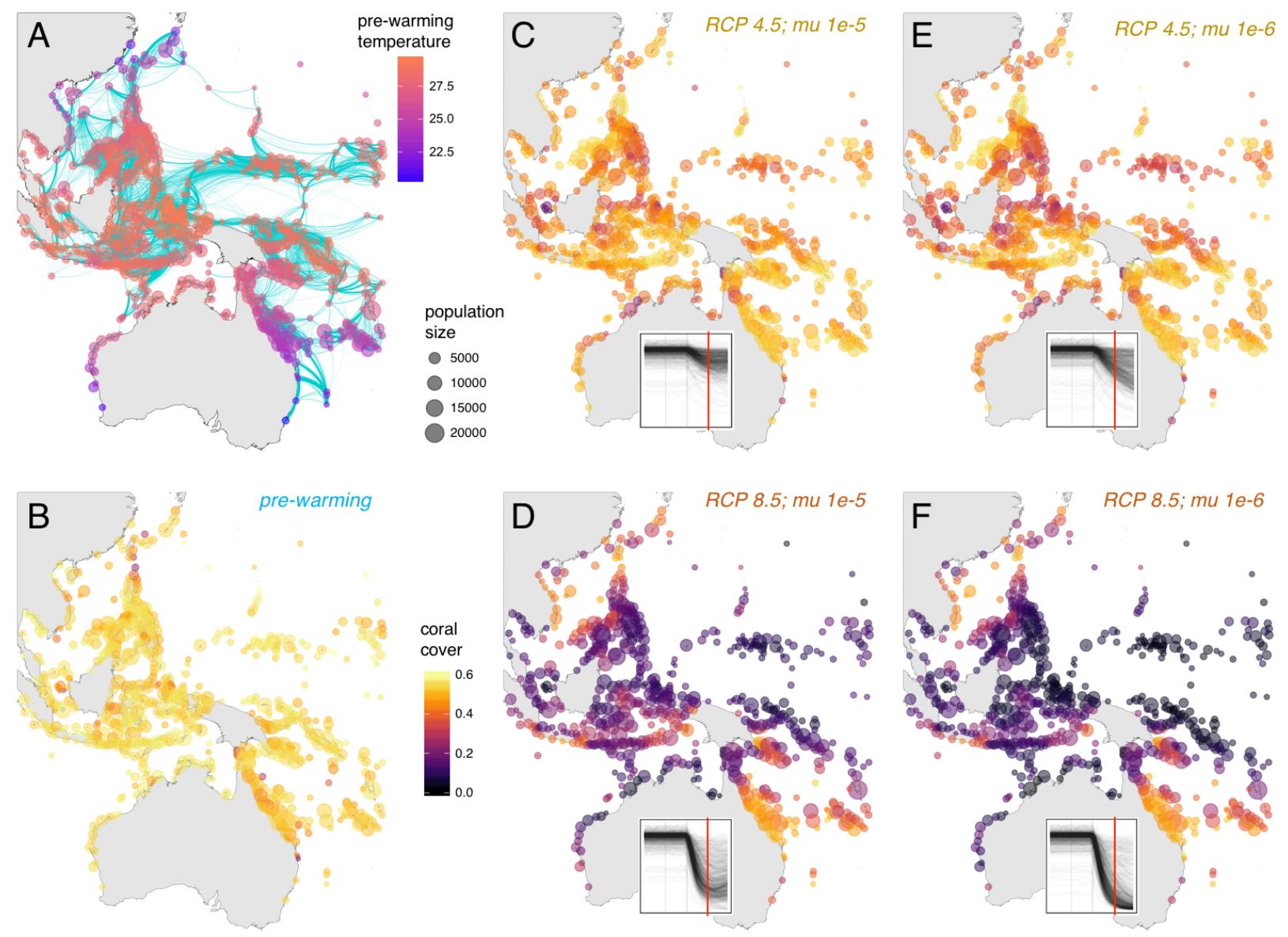

255 Figure 1. Response of coral cover ( $\%$ of occupied habitat) to the first 100 years of warming depends predominantly on the warming rate and not on genetic parameters. Sizes of points on all panels indicate habitat size at each location. A: Pre-warming temperatures and migration patterns. Migration (cyan arcs) are to be read clockwise to infer direction; arc line widths correspond to $0.1-1 \%, 1-10 \%$, and 10-100\% probability of migration. B: pre-warming coral cover. C,D: coral cover after 100 years of warming under RCP 4.5 (C) and RCP 8.5 (D) and mutation rate 1e-5 per locus per genome replication. E,F: the same as $\mathrm{C}$ and $\mathrm{D}$ but with tenfold lower mutation rate. Insets on panels $\mathrm{C}-\mathrm{F}$ show coral cover tracks for all reefs from 200 years before warming to 200 years after the onset of warming; red line marks 100 years of warming. settings, varying mostly in intensity (Fig. 1, Fig. 3, Supplemental video 1 , 
268 in the first century of warming (Fig. 1 C-F, insets; Fig. 3). Supporting the observation from our

269 previous model (Matz et al., 2018), warming resulted in an increase in magnitude of coral cover

270 response to thermal fluctuations, i.e., more severe coral mortality episodes in response to heat

271 waves (Fig. 2; this can also be seen in Supplemental video 1,

272 https://www.dropbox.com/s/ffv2zb164gwosld/slim triangle v4.mp4, as intensifying pulses of darker color).

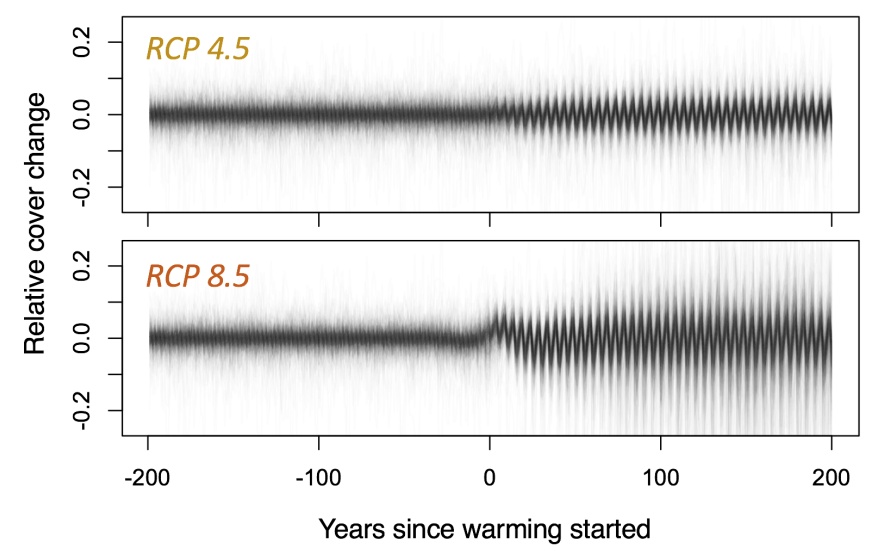

275 Figure 2. Coral cover changes (i.e, mortality-recovery cycles) in response to sinusoidal temperature

276 fluctuations intensify during warming. Lines for all 680 populations are overlaid; each line shows

277 deviation of the coral cover value relative to the smoothed mean.

279 Corals did much better overall under the slower warming rate (RCP 4.5, Fig. $1 \mathrm{C}, \mathrm{E})$ and low

280 juvenile mortality (Fig. 3). With all other parameter settings the responses were generally similar

281 in the first 100 years (Fig. 3), which is expected since the initial adaptive response is based

282 predominantly on standing genetic variation (i.e., it is mostly genetic rescue - redistribution of

283 pre-existing adaptive alleles among populations), and this variation stabilizes at similar levels

284 across parameter settings (Fig. S2). Only when standing genetic variation starts running out do

285 other settings, especially those affecting new mutations - fewer QTLs, lower mutation rate, and

286 lower mutation effect size - begin to have substantial influence (Fig. 3). These settings diminish 


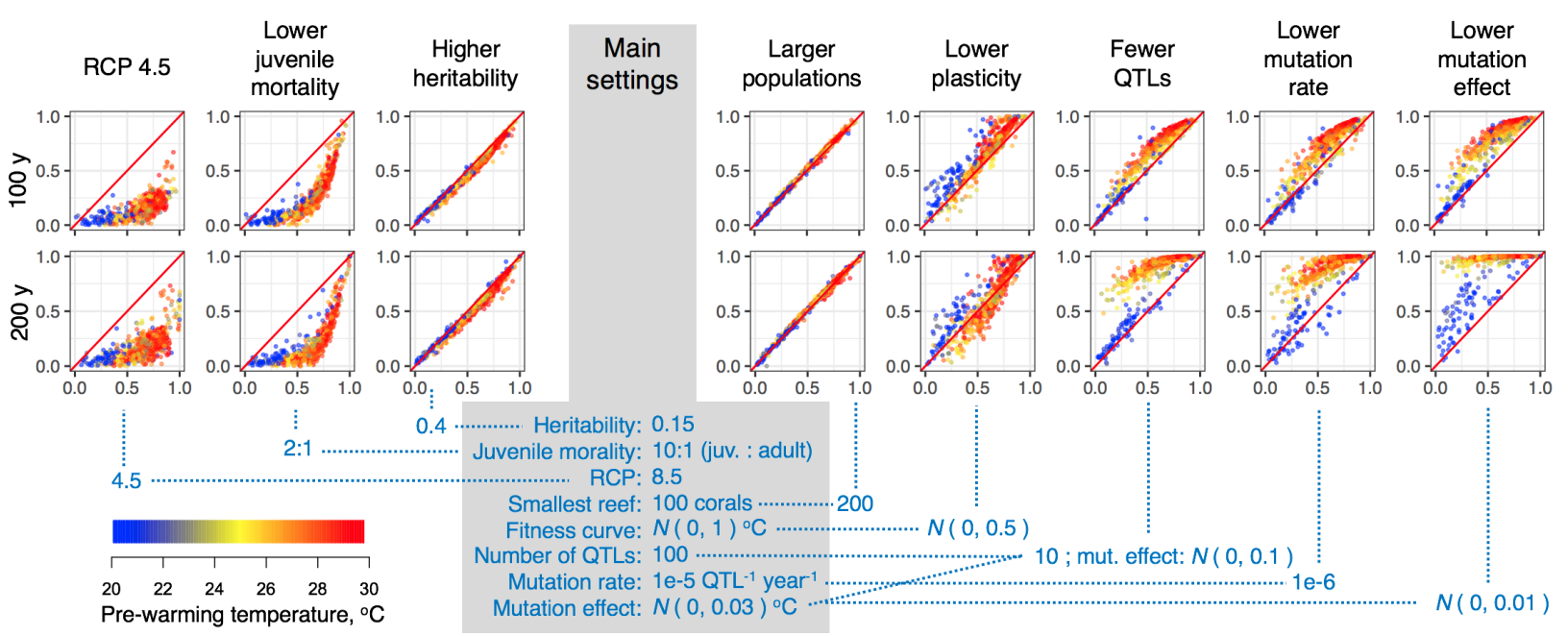

Figure 3. Comparisons of coral cover declines under different parameter settings, after 100 (first row of plots) and 200 (second row of plots) years of warming. Coral cover declines under alternative parameter settings (y axis) range from 0 (no decline) to 1 (extinction), and are plotted against declines observed under the "main settings" model (x-axis). Each model is different from the main in a single parameter indicated under the plots except the "Fewer QTLs" scenario, which had fewer QTLs and elevated mutation effect to keep the amount of mutational genetic variation constant. Colors indicate mean prewarming temperature of the reef (see legend). The red line on each panel is 1:1 correspondence. Declines in the first 100 years (first row of plots) are similar across parameter settings, with the notable exceptions of lower warming rate (RCP4.5) and lower juvenile mortality, both of which lead to faster population turnover relative to the rate of warming. After 200 years (second row of plots), many mid- and hightemperature reefs decline dramatically under settings that limit the influence of new adaptive mutations (“Fewer QTLs", "Lower mutation rate”, "Lower mutation effect”), preventing recovery via evolutionary rescue. 
strongest predictor of coral cover response to warming was pr05: the proportion of recruits that come from locations that are at least $0.5^{\circ} \mathrm{C}$ warmer (Fig. 4). This parameter essentially quantifies the potential of a reef to undergo genetic rescue via immigration of warm-adapted alleles. It alone explains $49 \%$ of variation in reef response under RCP 4.5 and $68 \%$ of variation under RCP
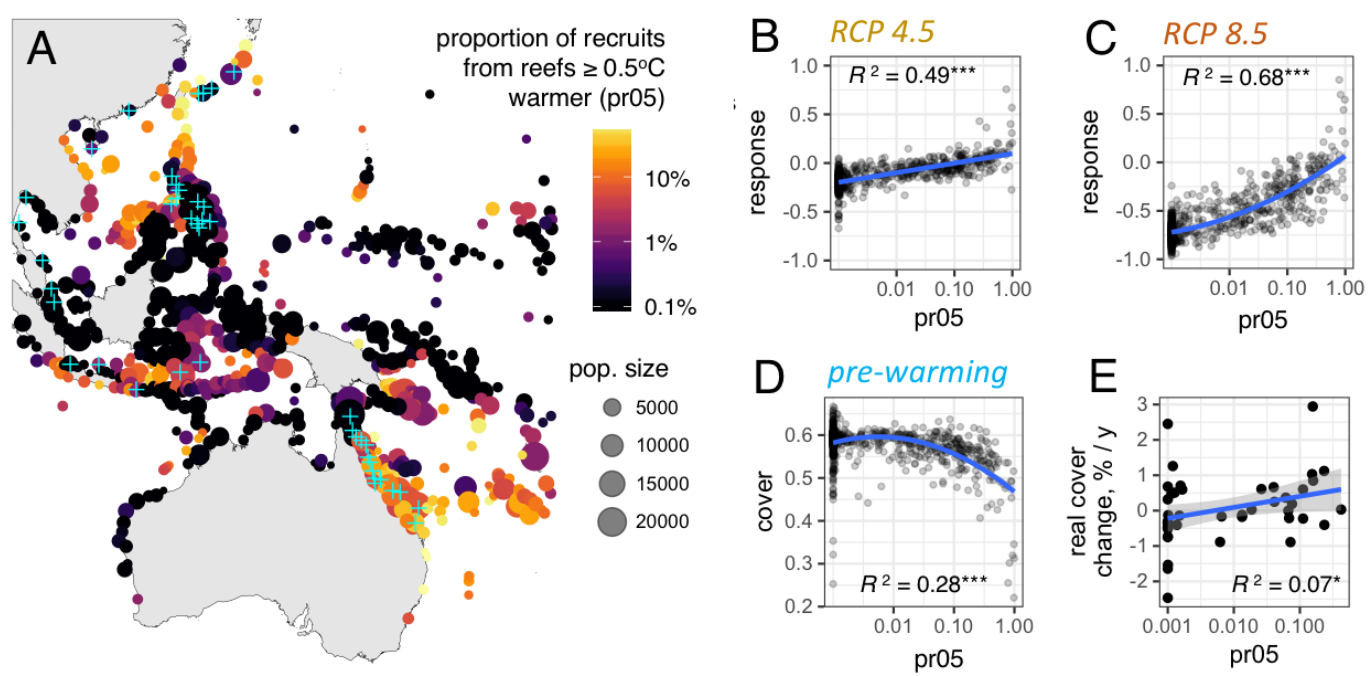

Figure 4. Immigration from warmer locations predicts reef response to warming. A: Map of pr05, the proportion of recruits immigrating from reefs that are at least $0.5^{\circ} \mathrm{C}$ warmer. Note the similarity of this pattern to the pattern of coral cover after 100 years of rapid warming (Fig. 1 D, F). The locations for which the actual long-term coral cover data were available (Bruno \& Selig, 2007) are marked by cyan crosses. $\mathrm{B}, \mathrm{C}$ : relationship between pr05 and coral cover response after 100 years of warming (negative $=$ decline, positive = increase), under RCP 4.5 (B) and RCP 8.5 (C). D: relationship between pr05 and prewarming coral cover: too much immigration from warmer locations interferes with local adaptation, but this effect is mild unless immigration is very high. E: correlation of pr05 and actual coral cover change over 15 years across the turn of the century, based on data from (Bruno \& Selig, 2007). On panels B-E, blue lines are regressions against $\log$ pr05 (linear on B and $\mathrm{E}$ and polynomial with degree 2 on $\mathrm{C}$ and $\mathrm{D}$ ). $95 \%$ confidence interval on panel $\mathrm{E}$ is grey, on B-D it is contained within the width of the line. *** $p<$ $1 \mathrm{e}-10 ; * p=0.04$. 
The influx of immigrants from warmer reefs is expected to interfere with local adaptation during the pre-warming period (Ronce \& Kirkpatrick, 2001), and indeed, we see a negative relationship between pr05 and pre-warming coral cover (Fig. 4 D). Still, pr05 on the order of $10 \%$ leads to relatively minor maladaptation pre-warming while fully protecting a reef from decline under RCP4.5 (Fig. 4 B) and alleviating half of the decline under RCP 8.5 (Fig. 4 C).
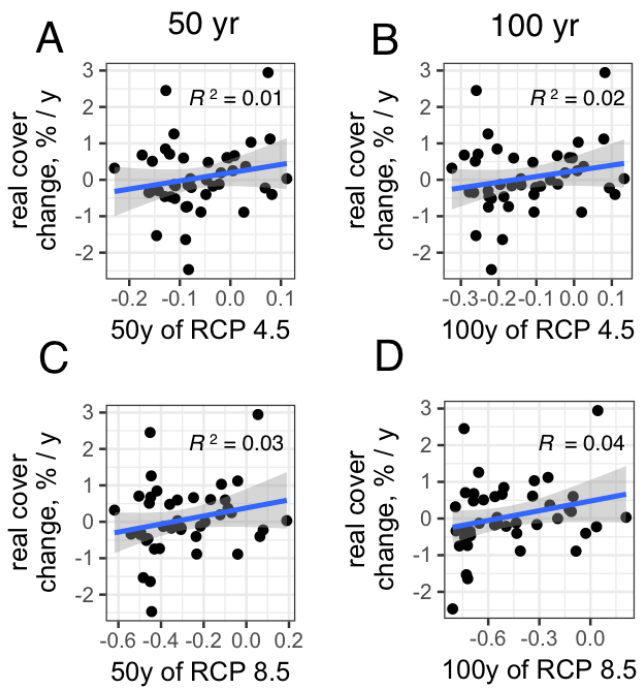

334 Figure S3. Relationship between model-predicted coral cover responses and actual coral cover change

335 over 15 years across the turn of the century (Bruno \& Selig, 2007). None of the correlations is statistically 336 significant, although the model predictions under RCP 8.5 scenario (C, D) are slightly more similar to the 337 actual changes.

339 Finally, pr05 was found to significantly correlate with the actual coral cover changes observed

340 throughout the region (Bruno \& Selig, 2007) (Fig. 4 E). At the same time, the correlation

341 between real changes and model-predicted changes either at 50 or 100 years of simulated

342 warming was not significant (Fig. S3). This is not very surprising since the model is an

343 abstraction of reality, not accounting for many relevant factors (most notably, ecological 
344 interactions, as we discuss below). Yet, it appears that our model did help to identify pr05 as an

345 important environmental predictor of coral resilience.

\section{DISCUSSION}

348 The world is already about 50 years into the warming scenario that we model (Pachauri et al.,

349 2015). Can evolution rescue corals from global warming? Yes and no. As long as we are willing

350 to assume that coral populations are genetically adapted to their local thermal regimes (Bay \&

351 Palumbi, 2014; Dixon et al., 2015; Palumbi et al., 2014), our model indicates that evolution is

352 going to protect at least some reefs from extinction for quite a while. Most notable of those are

353 reefs at the latitudinal range edge: Mid- and Southern Great Barrier Reef, New Caledonia,

354 Vietnam, Taiwan, and Japan (Fig. 1 D, F). Encouragingly, this protective effect was observed

355 even under rapid warming and limiting settings for novel genetic variation (Fig. $1 \mathrm{~F}$ ). The

356 surprising resilience of these reefs in our model is explained by the fact that they are major

357 downstream accumulation sites for adaptive genetic variation, drawing on heat-tolerant alleles

358 immigrating from warmer reefs throughout the whole region (Fig. 4). At least in theory, slow

359 rate of evolution should not be a problem there.

361 At the same time, many other regions, especially those that are already warm and don't receive

362 immigrants from yet warmer places (Fig. 4), are much more prone to dramatic declines due to

363 warming, even under mutation rates potentially allowing for indefinite evolution (Matz et al.,

364 2018) (Fig. 1 C, D). The state of these reefs critically depends on the single most important

365 parameter: the rate of warming relative to the rate of population turnover. Slower warming (RCP

3664.5 ) and low juvenile mortality (which leads to faster population turnover, Fig. S2) can 
367 dramatically offset declines of these reefs. Under warming rates predicted under RCP 4.5 (Fig.

368 S1 A), which assumes reduction of greenhouse gas emissions and stabilization of the greenhouse

369 effect by 2100, even the worst reef declines do not exceed 30-50\% (depending on other model

370 settings) within the first two centuries of warming (Fig. 1 C,E). In contrast, under the "business-

371 as-usual” RCP 8.5 scenario the majority of reefs near the equator and in Western Australia

372 decline to near-extinction within the first 100 years (Fig. $1 \mathrm{C}, \mathrm{E}$ ). While our model is likely

373 conservative in terms of allowed rate of accumulation of novel genetic variation due to low

374 assumed population size, and so these declines might be somewhat offset by new adaptive

375 mutations (evolutionary rescue), we believe that the model correctly reconstructs the general

376 shape of the initial response based on standing genetic variation.

378 It is important to emphasize that our model is purely population-genetic in the sense that it

379 assumes that any reef can recover without impediment as long as there is immigration and

380 recruitment. We do not account for possible ecological feedbacks that might limit reef recovery,

381 such as change in migration rates with warming (Munday et al., 2009), competition with algae

382 (McCook, Jompa, \& Diaz-Pulido, 2001), disease (Bruno et al., 2007), or transition of some coral

383 predator to devastating boom-and-bust population cycles, as happened with the crown-of-thorns

384 starfish (Kayal et al., 2012). We also don't account for the increase in storm severity (Emanuel,

385 2005), which is a major destructive force for many Indo-Pacific reefs (De'ath, Fabricius,

386 Sweatman, \& Puotinen, 2012). It is also important to note that for corals that mature and grow

387 slower than acroporids modeled here adaptation would be progressively unlikely, since slower

388 population turnover rate impairs adaptation just as much as the faster warming rate (Fig. 3). All

389 this means that even the best-protected reefs (according to our model) are still vulnerable to 
390 climate change. Although in theory they should be able to evolve rapidly enough, they remain

391 prone to all the other sources of mortality to which global warming contributes. Essentially, our

392 model provides a best-case scenario that can be used as a baseline to test for the role of other

393 factors in reef decline.

395 Should we consider helping corals evolve? While natural selection will always be much more 396 efficient than any lab-based selection because it has access to the vastly broader standing genetic

397 variation in nature, our results suggest one intervention that might help: facilitating genetic influx 398 from warmer locations, to raise the local pr05 (Fig. 4). This type of intervention is called 399 “assisted migration” (Haller, Mazzucco, \& Dieckmann, 2013) or “assisted gene flow” (Aitken \& 400 Whitlock, 2013), and would make particular sense on reefs that don't receive any natural 401 immigrants from warmer locations. Using cryopreserved sperm from warmer reefs to fertilize 402 local eggs and outplanting the juveniles would introduce otherwise inaccessible adaptive alleles 403 into the local population (Baums et al., 2019). While earlier works have proposed similar 404 interventions (Dixon et al., 2015; Kleypas et al., 2016; Matz et al., 2018), our current results 405 suggest the scale on which it has to be done. While even a small increase in pr05 already lowers 406 the risk of reef decline (Fig. 4 B, C), tangible effects are only observed when pr05 is on the order 407 of several percent or higher. This means that one would have to outplant warm-adapted recruits 408 in numbers approaching 5-10\% of total natural recruitment, which may or may not be realistic 409 depending on the coral species and the ocean basin. Our model can be used to estimate the 410 efficiency of such effort on specific reefs. 
412 All that said, by far the most helpful thing that we could do for coral reefs would be to curb

413 greenhouse gas emissions to push the global warming trajectory closer to the RCP 4.5 scenario.

414 According to the model presented here, slowing down of the warming rate would bring the most

415 substantial relief to struggling corals.

417 ACKNOWLEDGEMENTS

418 We are grateful to John F. Bruno for providing the compilation of coral cover data to compare

419 our model to real observations. This work was supported by the National Science Foundation

420 grant OCE-1737312 to M.V.M. This project relied on the high-performance computing resources

421 of the Texas Advanced Computing Center.

422

\section{REFERENCES}

424 Aitken, S. N., \& Whitlock, M. C. (2013). Assisted Gene Flow to Facilitate Local Adaptation to Systematics, Vol 44 (Vol. 44, pp. 367-+). Palo Alto: Annual Reviews.

427 Alvich, J. (n.d.). Earth System Model [Text]. Retrieved July 9, 2019, from https://www.gfdl.noaa.gov/earth-system-model/

429 Ayre, D. J., \& Hughes, T. P. (2004). Climate change, genotypic diversity and gene flow in reefbuilding corals. Ecology Letters, 7(4), 273-278. https://doi.org/10.1111/j.14610248.2004.00585.x of Three-Year-Old Acropora Millepora Corals Reared from Larvae in Northwestern Philippines [Text]. https://doi.org/info:doi/10.5343/bms.2011.1075 
435

436

437

438

439

440

441

442

443

444

445

446

447

448

449

450

451

452

453

454

455

456

457

Barrett, R. D. H., \& Schluter, D. (2008). Adaptation from standing genetic variation. Trends in Ecology \& Evolution, 23(1), 38-44. https://doi.org/10.1016/j.tree.2007.09.008

Barton, N. H., \& Turelli, M. (1989). Evolutionary quantitative genetics: how little do we know? Annual Review of Genetics, 23(1), 337-370. https://doi.org/10.1146/annurev.ge.23.120189.002005

Baums, I. B., Miller, M. W., \& Hellberg, M. E. (2005). Regionally isolated populations of an imperiled Caribbean coral, Acropora palmata. Molecular Ecology, 14(5), 1377-1390. https://doi.org/10.1111/j.1365-294X.2005.02489.x

Baums, Iliana B., Baker, A. C., Davies, S. W., Grottoli, A. G., Kenkel, C. D., Kitchen, S. A., ... Shantz, A. A. (2019). Considerations for maximizing the adaptive potential of restored coral populations in the western Atlantic. Ecological Applications, in press. https://doi.org/10.1002/eap.1978

Bay, R. A., \& Palumbi, S. R. (2014). Multilocus adaptation associated with heat resistance in reef-building corals. Current Biology: CB, 24(24), 2952-2956. https://doi.org/10.1016/j.cub.2014.10.044

Bay, R. A., Rose, N. H., Logan, C. A., \& Palumbi, S. R. (2017). Genomic models predict successful coral adaptation if future ocean warming rates are reduced. Science Advances, 3(11), e1701413. https://doi.org/10.1126/sciadv.1701413

Bruno, J. F., \& Selig, E. R. (2007). Regional Decline of Coral Cover in the Indo-Pacific: Timing, Extent, and Subregional Comparisons. PLoS ONE, 2(8). https://doi.org/10.1371/journal.pone.0000711

Bruno, J. F., Selig, E. R., Casey, K. S., Page, C. A., Willis, B. L., Harvell, C. D., ... Melendy, A. M. (2007). Thermal stress and coral cover as drivers of coral disease outbreaks. Plos 
Campbell-Staton, S. C., Cheviron, Z. A., Rochette, N., Catchen, J., Losos, J. B., \& Edwards, S. V. (2017). Winter storms drive rapid phenotypic, regulatory, and genomic shifts in the green anole lizard. Science (New York, N.Y.), 357(6350), 495-498.

Connolly, S. R., \& Baird, A. H. (2010). Estimating dispersal potential for marine larvae: dynamic models applied to scleractinian corals. Ecology, 91(12), 3572-3583. https://doi.org/10.1890/10-0143.1

466 https://doi.org/10.1126/science.aam5512

De'ath, G., Fabricius, K. E., Sweatman, H., \& Puotinen, M. (2012). The 27-year decline of coral cover on the Great Barrier Reef and its causes. Proceedings of the National Academy of Sciences of the United States of America, 109(44), 17995-17999. https://doi.org/10.1073/pnas.1208909109

Dixon, G. B., Davies, S. W., Aglyamova, G. V., Meyer, E., Bay, L. K., \& Matz, M. V. (2015). Genomic determinants of coral heat tolerance across latitudes. Science, 348(6242), 14601462. https://doi.org/10.1126/science. 1261224

Emanuel, K. (2005). Increasing destructiveness of tropical cyclones over the past 30 years. Nature, 436(7051), 686-688. https://doi.org/10.1038/nature03906

Haller, B. C., Mazzucco, R., \& Dieckmann, U. (2013). Evolutionary branching in complex landscapes. The American Naturalist, 182(4), E127-141. https://doi.org/10.1086/671907

Haller, B. C., \& Messer, P. W. (2019). SLiM 3: Forward Genetic Simulations Beyond the Wright-Fisher Model. Molecular Biology and Evolution, 36(3), 632-637. https://doi.org/10.1093/molbev/msy228

Hermisson, J., \& Pennings, P. S. (2005). Soft Sweeps: Molecular Population Genetics of 
Adaptation From Standing Genetic Variation. Genetics, 169(4), 2335-2352. https://doi.org/10.1534/genetics.104.036947

Hoegh-Guldberg, O. (1999). Climate change, coral bleaching and the future of the world's coral reefs. Marine and Freshwater Research, 50(8), 839-866. https://doi.org/10.1071/MF99078

Hoegh-Guldberg, O., Mumby, P. J., Hooten, A. J., Steneck, R. S., Greenfield, P., Gomez, E., ... Hatziolos, M. E. (2007). Coral reefs under rapid climate change and ocean acidification. Science, 318(5857), 1737-1742. https://doi.org/10.1126/science.1152509

Hoegh-Guldberg, Ove, Poloczanska, E. S., Skirving, W., \& Dove, S. (2017). Coral Reef Ecosystems under Climate Change and Ocean Acidification. Frontiers in Marine Science, 4, UNSP 158. https://doi.org/10.3389/fmars.2017.00158 https://www.hycom.org/publications/acknowledgements/hycom-data

494 Kayal, M., Vercelloni, J., de Loma, T. L., Bosserelle, P., Chancerelle, Y., Geoffroy, S., ... Adjeroud, M. (2012). Predator Crown-of-Thorns Starfish (Acanthaster planci) Outbreak, Mass Mortality of Corals, and Cascading Effects on Reef Fish and Benthic Communities.

498 Kleypas, J. A., Thompson, D. M., Castruccio, F. S., Curchitser, E. N., Pinsky, M., \& Watson, J. R. (2016). Larval connectivity across temperature gradients and its potential effect on heat tolerance in coral populations. Global Change Biology, 22(11), 3539-3549. https://doi.org/10.1111/gcb.13347 Cresko, W. A. (2015). Evolution of stickleback in 50 years on earthquake-uplifted 
islands. Proceedings of the National Academy of Sciences of the United States of America, 112(52), E7204-7212. https://doi.org/10.1073/pnas.1512020112

Matz, M. V., Treml, E. A., Aglyamova, G. V., \& Bay, L. K. (2018). Potential and limits for rapid genetic adaptation to warming in a Great Barrier Reef coral. PLOS Genetics, 14(4),

McCook, L. J., Jompa, J., \& Diaz-Pulido, G. (2001). Competition between corals and algae on coral reefs: a review of evidence and mechanisms. Coral Reefs, 19(4), 400-417. https://doi.org/10.1007/s003380000129

Munday, P. L., Leis, J. M., Lough, J. M., Paris, C. B., Kingsford, M. J., Berumen, M. L., \& Lambrechts, J. (2009). Climate change and coral reef connectivity. Coral Reefs, 28(2), 379-395. https://doi.org/10.1007/s00338-008-0461-9

Ocean Data Viewer. (n.d.). Retrieved July 9, 2019, from http://data.unep-wcmc.org/datasets/1

Orr, H. A. (2005). The genetic theory of adaptation: a brief history. Nature Reviews Genetics, 6(2), 119. https://doi.org/10.1038/nrg1523

Pachauri, R. K., Mayer, L., \& Intergovernmental Panel on Climate Change (Eds.). (2015).

521 Palumbi, S. R., Barshis, D. J., Traylor-Knowles, N., \& Bay, R. A. (2014). Mechanisms of reef coral resistance to future climate change. Science (New York, N.Y.), 344(6186), 895-898. https://doi.org/10.1126/science.1251336 
527

528

529

530

531

532

533

534

535

536

537

538

539

540

541

542

543

544

545

546

547

548

549

Quinn, T. M., Taylor, F. W., \& Crowley, T. J. (1993). A 173 year stable isotope record from a tropical south pacific coral 0. Quaternary Science Reviews, 12(6), 407-418. https://doi.org/10.1016/S0277-3791(05)80005-8

Romero-Torres, M., Treml, E. A., Acosta, A., \& Paz-García, D. A. (2018). The Eastern Tropical Pacific coral population connectivity and the role of the Eastern Pacific Barrier. Scientific Reports, 8(1), 9354. https://doi.org/10.1038/s41598-018-27644-2

Ronce, O., \& Kirkpatrick, M. (2001). When sources become sinks: migrational meltdown in heterogeneous habitats. Evolution; International Journal of Organic Evolution, 55(8), $1520-1531$.

Savolainen, O., Lascoux, M., \& Merilä, J. (2013). Ecological genomics of local adaptation. Nature Reviews Genetics, 14(11), 807-820. https://doi.org/10.1038/nrg3522

Smolarkiewicz, P. K. (1983). A Simple Positive Definite Advection Scheme with Small Implicit Diffusion. Monthly Weather Review, 111(3), 479-486. https://doi.org/10.1175/15200493(1983)111<0479:ASPDAS>2.0.CO;2

Torda, G., Donelson, J. M., Aranda, M., Barshis, D. J., Bay, L., Berumen, M. L., ... Munday, P. L. (2017). Rapid adaptive responses to climate change in corals. Nature Climate Change, 7(9), 627-636. https://doi.org/10.1038/nclimate3374

Treml, E. A., Roberts, J., Halpin, P. N., Possingham, H. P., \& Riginos, C. (2015). The emergent geography of biophysical dispersal barriers across the Indo-West Pacific. Diversity and Distributions, 21(4), 465-476. https://doi.org/10.1111/ddi.12307

Treml, E. A., Roberts, J. J., Chao, Y., Halpin, P. N., Possingham, H. P., \& Riginos, C. (2012). Reproductive Output and Duration of the Pelagic Larval Stage Determine Seascape-Wide Connectivity of Marine Populations. Integrative and Comparative Biology, 52(4), 525- 
551 Whiteley, A. R., Fitzpatrick, S. W., Funk, W. C., \& Tallmon, D. A. (2015). Genetic rescue to the rescue. Trends in Ecology \& Evolution, 30(1), 42-49. 